\title{
Obituario
}

\section{En la desaparición de un gran sociólogo: J.N. García Nieto}

\author{
Faustino Miguélez
}

Universitat Autonoma de Barcelona. Departament de Sociologia

08193 Bellatera (Barcelona). Spain

Juan Nepomuceno García Nieto no era un estudioso académico de la realidad social, como somos la mayoría, sino un estudioso de un mundo al que quería contribuir a transformar no sólo con su reflexión, sino con una acción coherente con aquélla. En cada ocasión que pude conversar con él, de cada artículo y libro suyos que he leído se desprende un gran deseo de comprender, buscando enfoques teóricos adecuados, leyendo infatigablemente, abriéndose a nuevas ideas, y una rigurosidad a toda prueba. Pero García Nieto tenía siempre un "para qué" en su actividad intelectual, salía del despacho y se sumergía en el contradictorio mundo del Baix Llobregat que le rodeaba. Prueba de que no iba equivocado no son sólo los numerosos recordatorios de su frgura, sino sobre rodo, la multitud de discípulos que ha dejado.

Como después del paso de todos los momentos buenos de nuestra vida que no hemos sabido aprovechar a fondo, lamento no haberlo conocido más y haber tenido otro trabajo, tántas veces que hubiera podido coincidir con él: soy alguien que echa de menos haberlo frecuentado poco, pero que cree que en este país le debemos algunas aportaciones para comprender mejor lo que nos rodea.

\section{El estudio del trabajo}

Mi primer encuentro humano e intelectual con García Nieto fuc en el Instituro de Estudios Laborales (IEL) de ESADE, estudiando las dificiles relaciones laborales de los años sesenta y setenta. Su Instituto era como una isla de libertad $y$ de pluralismo, pero también como una puerta por la que muchos líderes obreros entraban en lo que hasta entonces no había sido sino un coto reservado a los hijos de la burguesía catalana. Desde luego aquel Instituto era como una contradicción viviente para los futuros jóvenes empresartos y para muchos de sus profesores ( $y$ quizá por ello acabó como acabó), pero en aquellos ańos supuso una gran inyección intelectual para el movimiento obrero. Desde allí García Nicto y su equipo desartollaron y difundieron militantemente los primeros estudios serios en este pais sobre la conflictividad laboral, sobre las posibles formas de negociación de entonces, sobre el sindicato vertical, sobre ef nuevo movimiento obrero. 
Cada vez que to he leído, me ha dejado pasmado su Tiempos modernos y la enorme capacidad pedagógica que era capaz de desarrollar para explicar que debajo de una organización aparentemente técnica del trabajo había algo más. Este algo más no sólo eran estrategias e intereses diversos, concepciones distintas del trabajo y de sus usos, ideas contrapuestas sobre la empresa. Esto era lo que solían ver también otros académicos. Nepo también veía personas, algo que estorbaba a muchos que llegaban de las universidades europeas con la cabeza llena de "estructuras", "soportes", "formaciones sociales"... muy al uso en los primeros años setenta.

\section{La formación de la conciencia obrera}

El estudio del trabajo llevó a García Nieto (con Comín y otros) al estudio de una realidad mucho más profunda, las clases. Pero tampoco en este caso se trató de una implicación intelectual sin consecuencias. Estudiar y comprender la estructura de clases era para García Nieto comprenderlas desde dentro, en la vida cotidiana de las personas. Pero era también transformar una sociedad basada en la dominación y la desigualdad. García Nieto vivía en Cornellà porque quería comprender y porque quería transformar.

$\mathrm{Y}$ desde allí estudió y escribió libros y artículos extraordinariamente vigorosos sobre la conciencia de clase, sobre los cambios en el trabajo, sobre el papel de la innovación tecnológica en la conformación de mejores condiciones de vida para todos. Me he preguntado más de una vez por qué estaba tan convencido de los posibles buenos efectos de la innovación, él que no sólo leía mucho, sino que estaba inmerso en un contexto social de extraordinaria dure$z a$, sobre todo en años en los que las reestructuraciones y los cierres de empresa depauperan a muchas familias del Baix Llobregat. Siempre he encontrado una sola respuesta convincente, que él hizo el lema del núcleo político-intelectual que desarrolla en los últimos años: la «Utopía». No es posible pensar en una sociedad más solidaria y justa si no se cree en la utopía. García Nieto era un utópico, como más de uno decía de él con ánimo descalificador.

Hemos líegado al extremo de que la utopía está reñida con la política, porque ésta se define casi exclusivamente como una "gestión por objetivos", de la que queda muy alejada la educación de la gente en el bien colectivo, la ética y todos esos valores que, para liquidarlos sin sangre, algunos llaman simplemente dogmatismo. La utopía era una lección más contra el pragmatismo ramplón y alicorto de la misma izquierda gobernante. Sólo desde la potencialidad que da la utopia es posible pensar que tiene que llegar un día en el que el progreso sea de verdad bienestar material y moral para todos. Porque sólo si piensa esto muchísima gente, se obrará en consecuencia para lograrlo.

\section{La dualización de la sociedad}

En sus últimos años, García Nieto dedicó un importante esfuerzo a estudiar los efectos marginadores de la crisis y de la reestructuración en nuestras ciu- 
dades. También aquí creo que había captado uno de los fenómenos sociales más importantes de nuestro tiempo: la marginación de amplias capas de la población que puede abrir la puerta a un riesgo real de dualización de la sociedad, con una mayoría ampliamente "satisfecha" y una amplia minoría que sobrevive en condiciones muy alejadas de la primera.

Hay bastante gente que ha escrito sobre la nueva pobreza, sobre la sociedad dual, sobre la nueva marginación: con frecuencia son escritos que dibujan teóricamente el problema y sus causas, pero que escasamente se plantean soluciones, porque eso lo dejan para los políticos. Y quizá tienen razón, no lo niego. Pero García Nieto no era así: para él no tenía sentido describir y explicar sin señalar dónde estaban los problemas e indicar alguna posibilidad de resolverlos.

Muchos podrán pensar que su opción intelectual era arriesgada, porque buscando soluciones a los desequilibrios y desigualdades que veía podía perder la distancia objetiva y la neutralidad valorativa necesaria para analizar la realidad. Supongo que Nepo les diría - se lo oí alguna vez- que la neutralidad valorativa de muchos estudiosos es la forma más militante de luchar para que las cosas no cambien. La historia nos dirá, si la dejan, quién tenía razón. 